\title{
Use of Mini-FLOTAC and Fill-FLOTAC for rapidly diagnosing parasitic infections in zoo mammals
}

\author{
Utilização do Mini-FLOTAC e Fill-FLOTAC no diagnóstico rápido de infecçóes parasitárias de \\ mamíferos em zoológicos
}

\begin{abstract}
Michele Capasso ${ }^{1,2,3}$; Maria Paola Maurelli ${ }^{4}$; Davide Ianniello ${ }^{4}$; Leucio Camara Alves ${ }^{5 *}$ (D); Alessandra Amadesi ${ }^{4}$; Piero Laricchiuta ${ }^{6,7}$; Pasqualino Silvestre ${ }^{1}$; Marco Campolo $^{8}$; Giuseppe Cringoli ${ }^{4}$; Laura Rinaldi ${ }^{4}$
\end{abstract}

\author{
${ }^{1}$ Zoo di Napoli, Naples, NA, Italy \\ ${ }^{2}$ Zoo delle Star, Fossignano, LT, Italy \\ ${ }^{3}$ Zoo d'Abruzzo, Rocca San Giovanni, CH, Italy \\ ${ }^{4}$ Dipartimento di Medicina Veterinaria e Produzioni Animali, Università degli Studi di Napoli Federico II Naples, NA, Italy \\ ${ }^{5}$ Universidade Federal Rural de Pernambuco - UFRPE, Recife, PE, Brasil \\ ${ }^{6}$ Zoo Safari di Fasanolandia, Fasano, BR, Italy \\ ${ }^{7}$ Parco Faunistico Valcorba, Pozzonuovo, PD, Italy \\ ${ }^{8}$ Zoo delle Maitine, Pesco Sannita, BN, Italy
}

Received August 1, 2018

Accepted October 25, 2018

\begin{abstract}
Animals reared in restricted environments are highly susceptible to gastrointestinal infection by helminths and protozoa and therefore zoos are characterized as being parasite-rich environments. Successful implementation of control programs of these parasites in zoo environment depends upon precise and rapid diagnosing of gastrointestinal infections. The aim of this study was to demonstrate the role of the Mini-FLOTAC technique in combination with Fill-FLOTAC for rapidly diagnosing parasitic infections in zoo mammals. Fecal samples were collected from 70 animals in four different zoos located in central and southern Italy. All the samples were analyzed using Mini-FLOTAC in combination with Fill-FLOTAC. Out of the 70 pooled samples examined, 80\% (24/30) were positive for at least one parasite. Among the gastrointestinal nematodes, Strongyles were the most frequent (40\%), followed by Trichuris spp. (23.3\%), Parascaris spp. $(13.3 \%)$ and Capillaria spp. (3.3\%). Among the protozoa, Blastocystis spp., Giardia spp. and Eimeria spp. were detected in $6.6 \%, 3.3 \%$ and $3.3 \%$, respectively. These results show that Mini-FLOTAC in combination with Fill-FLOTAC can be used, not only for rapidly diagnosing parasitic infections in zoo mammals, but also for monitoring control programs in which large numbers of fecal samples need to be examined rapidly and reliably.
\end{abstract}

Keywords: Parasitological diagnosis, gastrointestinal parasites, zoo management.

\section{Resumo}

Animais criados em ambiente restritos são altamente suscetíveis a infecção gastrointestinal por helmintos e protozoários, constituindo os zoológicos em ambientes com alta contaminação por parasitos. $\mathrm{O}$ sucesso da implementaçáo de programas de controle contra estes parasitos em zoológicos depende do rápido diagnóstico das infecçóes por parasitas gastrointestinais. O objetivo deste estudo foi demonstrar o papel da técnica do Mini-FLOTAC em combinação com o Fill-FLOTAC no diagnóstico rápido das infecçôes parasitárias em mamíferos em zoológicos. Amostras de fezes foram coletadas de 70 animais de quatro diferentes zoológicos no centro e sudoeste da Itália. Todas as amostras foram analisadas pela técnica do Mini-FLOTAC em combinação com o Fill-FLOTAC. Do total de 70 pools de fezes examinadas, $80 \%$ (24/30) foram positivas para pelo menos um parasito. Entre os nematoides gastrointestinais a maior frequência foi observada para estrongilídeos (40\%), seguida por Trichuris spp. (23,3\%), Parascaris spp. (13,3\%) e Capillaria spp. (3,3\%). Entre os protozoários Blastocystis spp., Giardia spp. e Eimeria spp. foram detectados em 6,6\%, 3,3\% e 3,3\%, respectivamente. Estes resultados demonstram que a técnica do Mini-FLOTAC em combinação com o Fill-FLOTAC

*Corresponding author: Leucio Camara Alves. Departamento de Medicina Veterinaria, Universidade Federal Rural de Pernambuco - UFRPE,

Rua Manuel de Medeiros, s/n, Dois Irmãos, CEP 52171-900, Recife, PE,

Brasil. e-mail: leucioalves@gmail.com 
pode ser utilizada não somente para o diagnóstico rápido das infecçôes parasitárias em mamíferos em zoológicos, mas também no monitoramento de programas de controle onde grande número de amostras fecais devem ser examinadas de forma rápida e confiável.

Palavras-chave: Diagnóstico parasitológico, parasitos gastrointestinais, manejo em zoológicos.

\section{Introduction}

Currently, there are few reports on occurrences of gastrointestinal (GI) parasites in zoo mammals. Some of these studies only reported the local incidence and prevalence of infection in captivity. These animals infected by GI parasites are usually asymptomatic even when the parasite burden is heavy (SACHS \& SACHS, 1968). However, parasitic diseases constitute one of the major problems causing morbidity and mortality among them (GERAGHTY et al., 1982; VARADHARAJAN \& KANDASAMY, 2000; DOENHOFF et al., 2008; LIM et al., 2008).

Diagnosing of GI parasites is based on detection of eggs, larvae cysts and oocysts in stool samples through microscopic examination (TEN HOVE et al., 2009). These samples may have been obtained by using different parasitological techniques, such as direct examination, spontaneous sedimentation, centrifugation in ethyl acetate, centrifugal sedimentation in formalin-ether, centrifugal flotation with zinc sulfate, centrifugal flotation techniques with sucrose or flotation with sodium chloride. Thus, there are great divergences between the methods for diagnosing GI parasites, particularly with regard to sensitivity/specificity, cost and the time required for each method.

The Mini-FLOTAC technique was developed since 2013 as a novel direct method for diagnosing intestinal parasitic infections. Mini-FLOTAC attempts to address the challenge of using modern technology matched with high sensitivity and affordability. This procedure does not require any centrifugation step or expensive equipment; it can be performed on both fresh and fixed stool samples; and it requires less than 15 minutes of preparation before microscopic analysis (CRINGOLI et al., 2017).

Some degree of prophylactic anthelmintic treatment is necessary for many species of zoo mammals kept in captivity (BAIS et al., 2017). Parasite control is usually done at least twice a year or, alternatively, only if the fecal examination is positive. Therefore, the aim of this study was to demonstrate the role of the Mini-FLOTAC technique in combination with Fill-FLOTAC for rapidly diagnosing parasitic infections in zoo mammals.

\section{Materials and Methods}

This study was conducted at four zoos: two located in central Italy, Aprilia (413' $40^{\prime \prime} \mathrm{N}$; $\left.12^{\circ} 39^{\prime} 15^{\prime \prime} \mathrm{E}\right)$ and Lanciano $\left(42^{\circ} 13^{\prime} 37^{\prime \prime} \mathrm{N}\right.$; $\left.14^{\circ} 23^{\prime} 24^{\prime \prime} \mathrm{E}\right)$; and two in southern Italy, Naples $\left(40^{\circ} 51^{\prime} 22^{\prime \prime} \mathrm{N}\right.$; $\left.14^{\circ} 14^{\prime} 47^{\prime \prime} \mathrm{E}\right)$ and Pesco Sannita (41 $13^{\prime} 57^{\prime \prime} \mathrm{N}$; $\left.14^{\circ} 48^{\prime} 40^{\prime \prime} \mathrm{E}\right)$. In these zoos, exhibits are organized to ensure optimal usage of the available space and the natural environment is reproduced by creating habitats with dust, soil, wood, grass and endemic vegetation. The cages are cleaned daily using high-pressure piped water and dung is removed regularly. At the time of our study, non-human primates were kept under moderately crowded conditions, in temporary cages, pending the completion of new facilities in one of the zoos. At each institution, the zoo veterinarian is responsible for preventive health programs, which include health monitoring, parasite control and vaccination. Parasitological investigations are conducted at least twice per year, and animals are treated with antiparasitic drugs based on parasitological outcomes. Furthermore, the zoos are subject to the European Union Council Directive 92/65/EEC (Balai Directive), which outlines annual disease surveillance plans for approved establishments, along with animal transfer and quarantine procedures.

From June to August 2016, 70 fresh composite samples (pools) were collected by means of Fill-FLOTAC from animals in five mammal orders (Artiodactyla, Hyracoidea, Perissodactyla, Primates and Rodentia) at the zoos of Aprilia (8 pools), Lanciano (17 pools), Naples (16 pools) and Pesco Sannita (29 pools). The species in each zoo were sampled with the assistance of the animals' keepers. Sampling was conducted in the early morning using Fill-FLOTAC and the apical region of the feces deposited on the ground was collected. Each pool was composed of $2 \mathrm{~g}$ from each individual fecal sample (FAGIOLINI et al., 2010).

The Mini-FLOTAC technique was performed at the zoo facilities and two different flotation solutions were used: FS2 (sodium chloride, specific gravity [SG] = 1.200; AppliChem, Brentwood, MO, USA) and FS7 (zinc sulfate, SG = 1.350; AppliChem). Magnifications of 100x and 400x were used to identify helminth eggs and protozoan cysts/oocysts. The results were expressed as the arithmetic mean number of eggs/oocysts/cysts per gram (EPG/OPG/CPG) of feces.

\section{Results}

Mini-FLOTAC was shown to be a simple and rapid technique for detecting the number of eggs/cysts/oocysts per gram of feces. Among the 70 pools analyzed, 80\% (24/30; 95\% confidence interval $[\mathrm{CI}]=30-54 \%$ ) were positive for at least one parasite (Table1).

Parasite intensity express in eggs, larvae, cysts and oocyst per gram (EPG, LPG, CPG and OPG) of feces detected in zoo mammals are showed in Table 2.

Higher prevalence of parasites was detected in the zoos in central Italy (Lanciano 47\% and Aprilia 37.5\%) than in the zoos in southern Italy (Naples 37.5\% and Pesco Sannita 20.1\%).

Several genera of helminths and protozoa were detected in mammals at the four zoos. Among the nematodes, GI strongyles were the most frequent (40\%), followed by Trichuris spp. (23.3\%), Parascaris spp. (13.3\%) and Capillaria spp. (3.3\%). With regard to protozoa, most of the samples were positive for Blastocystis spp. (6.6\%), followed by Giardia spp. (3.3\%) and Eimeria spp. (3.3\%). 
Table 1. Parasitological stool test results, according to mammal orders, in the central and southern Italian zoos.

\begin{tabular}{lccc}
\hline $\begin{array}{c}\text { Order of zoo } \\
\text { mammals }\end{array}$ & Pools examined & Positive pools & $\mathbf{( \% )}$ \\
\hline Artiodactyla & 31 & 11 & 35.4 \\
Carnivora & 9 & 0 & 0 \\
Chiropthera & 1 & 0 & 0 \\
Diprodotondia & 4 & 0 & 0 \\
Hyracoidea & 1 & 0 & 0 \\
Perissodactyla & 9 & 6 & 66.6 \\
Primates & 10 & 5 & 50 \\
Proboscidea & 1 & 0 & 0 \\
Rodentia & 4 & 2 & 50 \\
Total & $\mathbf{7 0}$ & $\mathbf{2 4}$ & $\mathbf{3 4 . 3}$ \\
\hline
\end{tabular}

Table 2. Parasite intensity (minimum, mean, and maximum) of eggs/oocysts/cysts per gram (EPG/OPG/CPG) of feces detected in zoo mammals in central and southern Italy by Mini-FLOTAC combined with fill FLOTAC techniques.

\begin{tabular}{|c|c|c|c|c|}
\hline \multirow{3}{*}{ Parasitic Group/Genus } & \multirow{3}{*}{$\begin{array}{c}\text { No.pos. } \\
(\%)\end{array}$} & \multicolumn{3}{|c|}{ Mini-FLOTAC } \\
\hline & & \multicolumn{3}{|c|}{$\begin{array}{c}\text { Intensity } \\
\left(\mathrm{EPG} / \mathrm{OPG} / \mathrm{CPG}^{*}\right)\end{array}$} \\
\hline & & Min & Mean & Max \\
\hline \multicolumn{5}{|l|}{ Helminths } \\
\hline GI strongyles & $12(17)$ & 5 & 78 & 370 \\
\hline Trichuris & $7(10)$ & 5 & 20 & 40 \\
\hline Parascaris & $4(6)$ & 5 & 10 & 15 \\
\hline Capillaria & $1(1)$ & 0 & 8 & 10 \\
\hline Nematodirus & $1(1)$ & 0 & 4 & 4 \\
\hline \multicolumn{5}{|l|}{ Protozoa } \\
\hline Eimeria & $1(1)$ & 0 & 35 & 35 \\
\hline Blastocystis & $2(3)$ & ++ & + & + \\
\hline Entamoeba coli & $1(1)$ & - & + & + \\
\hline Giardia & $1(1)$ & - & + & + \\
\hline
\end{tabular}

${ }^{*}$ CPG: $+=1$ cyst per microscopic field; $++=3$ cysts per microscopic field.

\section{Discussion}

In this study, we showed the ability of the Mini-FLOTAC technique to detect GI parasites in different species of zoo mammals. The different flotation solutions used in this study appeared to increase the detected recovery rates for eggs, cysts and oocysts in all samples. This is a big advantage in comparison with other copro-microscopic methods, in which only one solution is used to perform the tests.

Mini-FLOTAC in combination with Fill-FLOTAC ensured a high level of safety for the operator. In fact, Fill-FLOTAC equipped with a collector/homogenizer allows sampling and processing of fecal samples without coming into contact with them. It operates as a closed system and therefore not only provides protection for the operator but also enables the possibility of sample preservation in formalin for subsequent processing.

Furthermore, the present study highlighted the presence of parasitic elements in samples from zoo mammals despite regular administration of anthelminthic drugs. Widespread presence of GI parasites was confirmed in the four zoos. Helminthic infections were more common than protozoan infections in all the mammal orders examined and this was concordant with the findings from two other Italian zoos located in Apulia and Tuscany, where the overall prevalence of parasitic infection was $61.5 \%(96 / 156)$ by flotation test using a low-specific-gravity solution, sedimentation and a modified McMaster technique (FAGIOLINI et al., 2010).

All of the gastrointestinal parasites identified in our study were described previously in zoo animals by other authors, and these parasites are known to be pathogenic to both animals and humans (animal handlers and zoo visitors) (FONTENOT et al., 2008; FAGIOLINI et al., 2010; TAHAS \& DIAKOU, 2013; MAESANO et al., 2014; NOSAL et al., 2016; CRINGOLI et al., 2017). Gastrointestinal parasites of zoo mammals include zoonotic species and therefore their presence raises public health concerns, particularly Blastocystis spp. and Giardia spp. (GOOSSENS et al., 2005; LEVECKE et al., 2007).

Some authors have reported the possibility that these protozoa may be transmitted to humans or other animals (RAJAH SALIM et al., 1999). Transmission between animals and humans in association with clinical outbreaks among animal keepers has been reported in various studies (MILLER et al., 2004; LEVECKE et al., 2007; BERRILLI et al., 2011). The presence of zoonotic parasites emphasizes the need to use rapid copro-microscopic techniques and specific devices that protect the operator.

This was the first study in which Mini-FLOTAC in combination with Fill-FLOTAC was used for rapidly diagnosing parasitic infections in zoo mammals. Currently, to make diagnoses of GI parasites in zoo animals, routine coprological procedures such as direct and indirect wet-mount preparations or the McMaster method are used (MALAN et al., 1997; PÈREZ CORDÒN et al., 2008; LEVECKE et al., 2010). Achieving accurate rapid diagnoses is a critical point in enabling control over parasitic infections.

In conclusion, Mini-FLOTAC in combination with Fill-FLOTAC was shown to be user-friendly and safe, with a wide diagnostic range (protozoa and helminths). These features are particularly useful for monitoring and control programs in which large numbers of fecal samples need to be processed rapidly and safely.

\section{Acknowledgements}

We thank the directors of the four zoos for permission to conduct our study. We are also grateful to the zoo vets and keepers for their help with sampling.

\section{References}

Bais B, Tak L, Mahla S. Study of preventive health measures for wildlife in captivity: a review of management approaches. Int J Avian Wildl Biol 2017; 2(3): 73-75.

Berrilli F, Prisco C, Friedrich KG, Di Cerbo P, Di Cave D, De Liberato C. Giardia duodenalis assemblages and Entamoeba species infecting non-human primates in an Italian zoological garden: zoonotic potential and management traits. Parasit Vectors 2011; 4(1): 199. http://dx.doi. org/10.1186/1756-3305-4-199. PMid:21988762. 
Cringoli G, Maurelli MP, Levecke B, Bosco A, Vercruysse J, Utzinger $\mathrm{J}$, et al. The Mini-FLOTAC technique for the diagnosis of helminth and protozoan infections in humans and animals. Nat Protoc 2017; 12(9): 1723-1732. http://dx.doi.org/10.1038/nprot.2017.067. PMid:28771238.

Doenhoff MJ, Cioli D, Utzinger J. Praziquantel: mechanisms of action, resistance and new derivatives for schistosomiasis. Curr Opin Infect Dis 2008; 21(6): 659-667. http://dx.doi.org/10.1097/QCO.0b013e328318978f. PMid:18978535.

Fagiolini M, Lia R, Laricchiuta P, Cavicchio P, Mannella R, Cafarchia $\mathrm{C}$, et al. Gastrointestinal parasites in mammals of two Italian zoological gardens. J Zoo Wildl Med 2010; 41(4): 662-670. http://dx.doi. org/10.1638/2010-0049.1. PMid:21370648.

Fontenot DK, Kinney-Moscona A, Kaplan RM, Miller J. Effects of copper oxide wire particle bolus therapy on trichostrongyle fecal egg counts in exotic artiodactylids. J Zoo Wildl Med 2008; 39(4): 642-645. http://dx.doi.org/10.1638/2007-0069.1. PMid:19110710.

Geraghty V, Mooney J, Pike K. A study of parasitic infections in mammals and birds at the Dublin Zoological Gardens. Vet Res Commun 1982; 5(4): 343-348. PMid:7157643.

Goossens E, Dorny P, Boomker J, Vercammen F, Vercruysse J. A 12-month survey of the gastro-intestinal helminths of antelopes, gazelles and giraffids kept at two zoos in Belgium. Vet Parasitol 2005; 127(3-4): 303-312. http:// dx.doi.org/10.1016/j.vetpar.2004.10.013. PMid:15710531.

Levecke B, Dorny P, Geurden T, Vercammen F, Vercruysse J. Gastrointestinal protozoa in non-human primates of four zoological gardens in Belgium. Vet Parasitol 2007; 148(3-4): 236-246. http://dx.doi.org/10.1016/j. vetpar.2007.06.020. PMid:17656023.

Levecke B, Dreesen L, Dorny P, Verweij JJ, Vercammen F, Casaert S, et al. Molecular identification of Entamoeba spp. in captive nonhuman primate. J Clin Microbiol 2010; 48(8): 2988-2990. http://dx.doi.org/10.1128/ JCM.00013-10. PMid:20573870.

Lim YA, Ngui R, Shukri J, Rohela M, Mat Naim HR. Intestinal parasites in various animals at a zoo in Malaysia. Vet Parasitol 2008; 157(1-2): 154159. http://dx.doi.org/10.1016/j.vetpar.2008.07.015. PMid:18723289.

Maesano G, Capasso M, Ianniello D, Cringoli G, Rinaldi L. Parasitic infections detected by FLOTAC in zoo mammals from Warsaw, Poland.
Acta Parasitol 2014; 59(2): 343-353. http://dx.doi.org/10.2478/s11686014-0249-8. PMid:24827109.

Malan FS, Horak IG, de Vos V, Van Wyk JA. Wildlife parasites: lessons for parasite control in livestock. Vet Parasitol 1997; 71(2-3): 137-153. http://dx.doi.org/10.1016/S0304-4017(97)00030-7. PMid:9261975.

Miller MA, Grigg ME, Kreuder C, James ER, Melli AC, Crosbie PR, et al. An unusual genotype of Toxoplasma gondii is common in California sea otters (Enhydra lutris nereis) and is a cause of mortality. Int J Parasitol 2004; 34(3): 275-284. http://dx.doi.org/10.1016/j.ijpara.2003.12.008. PMid:15003489.

Nosal P, Kowal J, Kornaś S, Wyrobisz A, Skotnicki J, Basiaga M, et al. Endoparasites of exotic ungulates from the Giraffidae and Camelidae families kept ex situ. Ann Parasitol 2016; 62(1): 67-70. PMid:27262960.

Pérez Cordón G, Hitos Prados A, Romero D, Sánchez Moreno M, Pontes A, Osuna A, et al. Intestinal parasitism in the animals of the zoological garden "Peña Escrita" (Almuñecar, Spain). Vet Parasitol 2008; 156(3-4): 302-309. http://dx.doi.org/10.1016/j.vetpar.2008.05.023. PMid:18639383.

Rajah Salim H, Suresh Kumar G, Vellayan S, Mak JW, Khairul Anuar A, Init I, et al. Blastocystis in animal's handlers. Parasitol Res 1999; 85(12): 1032-1033. http://dx.doi.org/10.1007/s004360050677. PMid:10599928.

Sachs R, Sachs C. A survey of parasitic infestation of wild herbivores in the Serengeti region in northern Tanzania and the Lake Rukwa region in southern Tanzania. Bull Epizoot Dis Afr 1968; 16(4): 455-472. PMid:5753463.

Tahas SA, Diakou A. Persistent Giardia spp. and Trichuris spp. infection in Maras (Dolichotis patagonum) at a zoo in Greece. J Zoo Wildl Med 2013; 44(2): 389-394. http://dx.doi.org/10.1638/2012-0191R.1. PMid:23805557.

Ten Hove RJ, van Esbroeck M, Vervoort T, Van den Ende J, Van Lieshout L, Verweij JJ. Molecular diagnostics of intestinal parasites in returning travelers. Eur J Clin Microbiol Infect Dis 2009; 28(9): 1045-1053. http:// dx.doi.org/10.1007/s10096-009-0745-1. PMid:19415354.

Varadharajan A, Kandasamy A. A survey of gastro-intestinal parasites of wild animals in captivity in the V.O.C park and mini zoo, coimbatore. Zoos' Print J 2000; 15(5): 257-258. http://dx.doi.org/10.11609/JoTT. ZPJ.15.5.257-8. 